\title{
CORRECTION
}

View Article Online

View Journal | View Issue

\section{D) Check for updates \\ Correction: Effects of droplet size and surfactants on anchoring in liquid crystal nanodroplets}

Cite this: Soft Matter, 2020,

16, 10386

Zeynep Sumer and Alberto Striolo*

Correction for 'Effects of droplet size and surfactants on anchoring in liquid crystal nanodroplets' by

DOI: $10.1039 / \mathrm{d} 0$ sm90223c

Zeynep Sumer et al., Soft Matter, 2019, 15, 3914-3922, DOI: 10.1039/C9SM00291J.

rsc.li/soft-matter-journal

The authors regret an error with ref. 24 in the original article, where one of the authors is missing from the list. The correct ref. 24 is shown as ref. 1 below.

The Royal Society of Chemistry apologises for these errors and any consequent inconvenience to authors and readers.

\section{References}

1 H. Tsujinoue, T. Inokuchi and N. Arai, Liq. Cryst., 2019, 46, 1428-1439. 